\title{
Malaysia Healthcare Early Response in Combatting COVID-19 Pandemic in 2020
}

\author{
Safiya Amaran', Ahmad Zulfahmi Mohd Kamaruzaman ${ }^{2,3}$, Nurul Yaqeen Mohd Esa ${ }^{4}$, Zaharah Sulaiman ${ }^{2, *}$ \\ ${ }^{1}$ Faculty of Medicine, Universiti Sultan Zainal Abidin, Kuala Terengganu, Malaysia \\ ${ }^{2}$ School of Medical Sciences, Universiti Sains Malaysia, Kubang Kerian, Malaysia \\ ${ }^{3}$ Training Management Division, Ministry of Health Malaysia, Putrajaya, Malaysia \\ ${ }^{4}$ Sunway Medical Centre Velocity, Kuala Lumpur, Malaysia
}

\begin{abstract}
The year 2020 saw the emergence of a novel coronavirus - the severe acute respiratory syndrome coronavirus 2which has led to an unprecedented pandemic that has shaken the entire world. The pandemic has been a new experience for Malaysia, especially during the implementation of large-scale public health and social measures called the Movement Control Order (MCO). This paper seeks to describe the experiences of the Malaysian healthcare system thus far in combatting the pandemic. The Malaysian healthcare system comprises two main arms: public health and medicine. The public health arm focuses on early disease detection, contact tracing, quarantines, the MCO, and risk stratification strategies in the community. The medical arm focuses on the clinical management of coronavirus disease 2019 (COVID-19) patients; it encompasses laboratory services, the devising of clinical setting adjustments, and hospital management for COVID-19 and non-COVID-19 patients. Malaysia experienced intense emotions at the beginning of the pandemic, with great uncertainty regarding the pandemic's outcome, as the world saw a frighteningly high COVID-19 mortality. As of writing (May 30, 2020), Malaysia has passed the peak of its second wave of infections. The experience thus far has helped in preparing the country's healthcare system to be vigilant and more prepared for future COVID-19 waves. To date, the pandemic has changed many aspects of Malaysia's life, and people are still learning to adapt to new norms in their lives.
\end{abstract}

Keywords: COVID-19; Malaysia; Healthcare; Public Health; Disease Management; Pandemic

Received: May 18, 2020, Revised: June 14, 2020, Accepted: June 18, 2020

*Corresponding Author: Zaharah Sulaiman https://orcid.org/0000-0002-4023-1845

Tel: +60-197585172, Fax: +60-97656532,E-mail: zaharah@usm.my 


\section{INTRODUCTION}

The emergence of a novel coronavirus-the severe acute respiratory syndrome coronavirus 2 (SARS-CoV-2)-has startled the entire world. A novel virus means every human being is susceptible to infection, as no one yet has developed immunity against it. Hence, anyone can get infected with coronavirus disease 2019 (COVID-19) if exposed to it. In particular, the fatality rate of the disease is significantly higher among the elderly and among people with comorbidities. ${ }^{1)}$ Unlike other diseases caused by coronavirus like severe acute respiratory syndrome (SARS) first reported in 2003 and the Middle East respiratory syndrome first reported in 2012, which mainly affect a person's lower respiratory tract, COVID-19 affects both the upper and lower respiratory tracts, resulting in a wide variety of manifestations, from asymptomatic and mildly symptomatic conditions to a fatal respiratory condition called acute respiratory distress syndrome. ${ }^{1)}$

The first confirmed case of COVID-19 was diagnosed on December 1, 2019 in Wuhan, China, ${ }^{2)}$ which became the initial epicenter of what would become a global pandemic. Learning from their SARS experience in 2003-2004, with the SARS epidemic, China acted rapidly and implemented a total lockdown called cordon sanitaire, which has been described as "the largest quarantine in human history." ${ }^{3)}$ The lockdown was implemented in Wuhan on January 23, 2020, and similar restrictions were later extended to 15 cities in the rest of Hubei province-affecting approximately 57 million people-to suppress the pandemic. ${ }^{4)}$ Authorities immediately prepared 16 temporary hospitals in response to a sudden massive demand for healthcare services due to the large number of cases. ${ }^{5}$ The high number of COVID-19 cases and mortality in Wuhan was especially frightening, and countries worldwide were observing China while making their own preparations. The COVID-19 outbreak was declared by the World Health Organization (WHO) as a "public health emergency of international concern" on January 30, and was later announced as a pandemic on March 11, due to rapid increase in the number of cases involving a growing number of countries.

\section{HEALTHCARE PREPARATIONS FOR THE COVID-19 PANDEMIC IN MALAYSIA}

The Malaysian healthcare system began to prepare for COVID-19 since it first emerged in Wuhan. A preparedness plan was initiated by Ministry of Health Malaysia since early January 2020, which covered preparations in areas encompassing public health, clinical management, and laboratory capacity. COVID-19 screening using thermal scanners was implemented at all international points of entry in Malaysia. ${ }^{6}$ As of May 2020, there are 79 thermal scanners located throughout Malaysia. ${ }^{7)}$ With these scanners, visitors with a fever can be detected and checked for other respiratory-related symptoms. Nonetheless, despite thorough gatekeeping procedures, infected persons may pass undetected if they are afebrile and show no such symptoms. At the beginning of the pandemic, 57 hospitals were initially prepared for con- ducting COVID-19 screenings, and 28 hospitals were allocated for receiving and treating COVID-19 patients, with at least one hospital per state. In terms of diagnostic tests, the Institute for Medical Research (IMR) prepared employment of the reverse transcriptase polymerase chain reaction (RT-PCR) test to diagnose COVID-19 from the SARS$\mathrm{CoV}-2$ genome sequence that has been shared by China. With this test, authorities in Malaysia are able to detect a person carrying the SARS$\mathrm{CoV}-2$ virus. In the initial stage of the pandemic, the IMR was the only laboratory involved in conducting RT-PCR testing in Malaysia, which is the gold standard for testing widely used globally.

In January 2020, travelers from China were still allowed to enter Malaysia, but anyone from Wuhan with any symptoms of COVID-19 immediately had to be screened for the virus in designated screening centers, which was how the country's initial cases were detected. The pandemic in Malaysia started as a small wave on January 25 in Johor Bharu, when three individuals who traveled from Wuhan tested positive for the coronavirus. ${ }^{8)}$ All cases were admitted and treated accordingly in the isolation ward despite their mild symptoms; some COVID-19 cases have very mild symptoms but are still admitted to the isolation ward to prevent further spread of the virus.

Contact tracing was initiated following the detection of positive cases in Malaysia as an immediate control and preventive measure. If a person is known to have been in close contact with a confirmed case, the local district health office requires that the person quarantines for 14 days, according to the average incubation period of COVID-19 reported by the WHO. ${ }^{1)}$ Adherence is compulsory under the Control and Prevention of Infectious Diseases Act, 1988. If a close contact has a fever or other respiratory-related symptoms, he or she is defined as a person under investigation (PUI) and needs to be hospitalized for further clinical management. ${ }^{9)}$

\section{HEALTHCARE RESPONSES TO COMMUNITY TRANSMISSION OF COVID-19 IN MALAYSIA}

The first COVID-19 case involving a Malaysian was detected on February 5, 2020. Further investigation by Johor State Health Department found that the person infected could have contracted the disease while attending an event in Singapore, which included participants from Wuhan. The cluster that emerged as a result of this event marked the beginning of local transmission in the country, when the infected Malaysian's family members also became infected. Since the case's detection, the surveillance system of Malaysia has been strengthened to monitor daily and weekly trends in all sentinel health centers in the country. The surveillance includes looking for influenza-like illness (ILI) in health clinics and severe acute respiratory illness (SARI) in government hospitals. ${ }^{10)}$

Reported cases remained relatively low throughout February 2020 until a large spike of cases became apparent in the middle of March (Figure 1), which marked the beginning of the second wave, brought by the Sri Petaling cluster. The first COVID-19 case detected via SARI surveillance in Pahang on March 12 was later traced to the Sri Petaling 


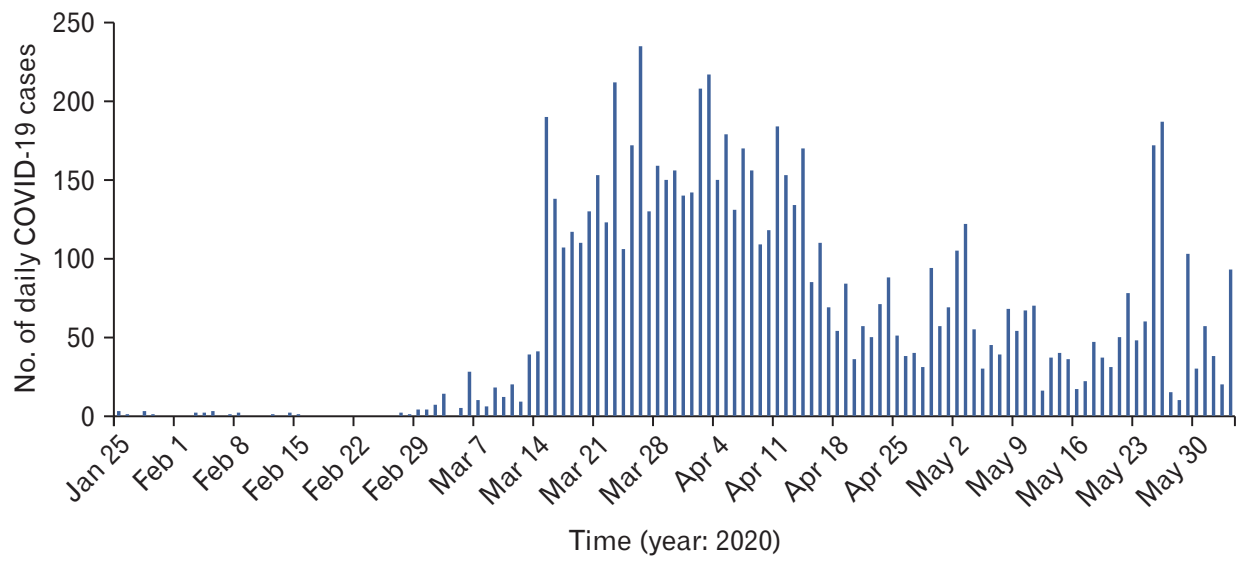

COVID-19 cases according to state and regions as of June 5, 2020

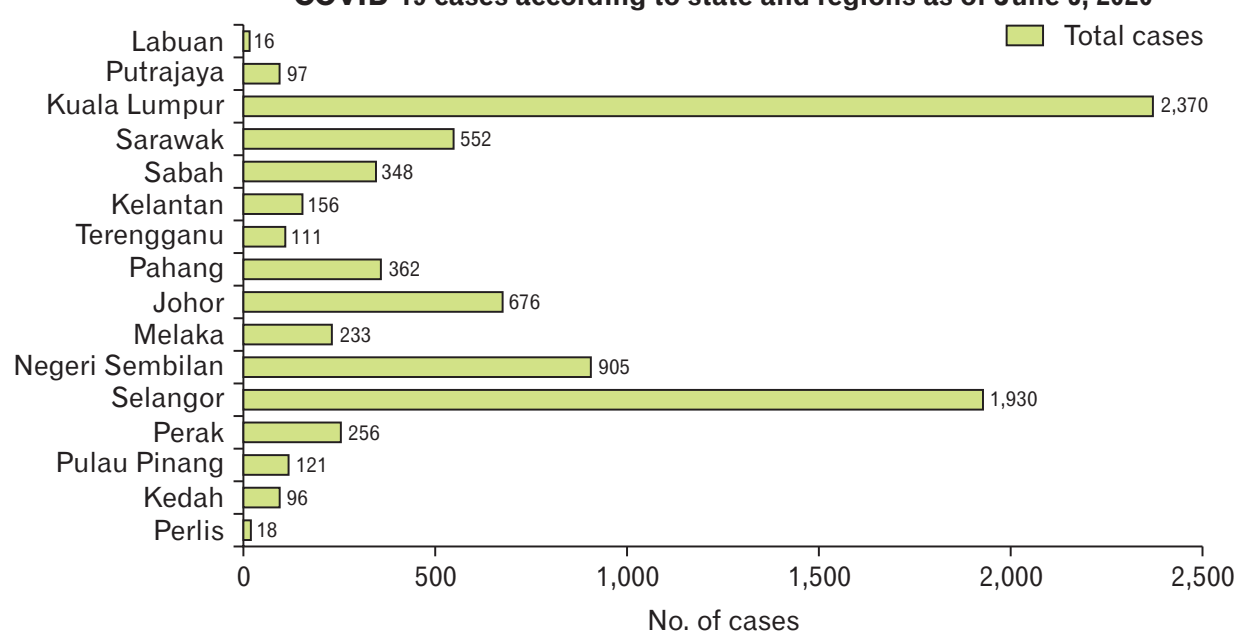

Figure 1. Number of daily coronavirus disease 2019 (COVID-19) cases in Malaysia as of May $30,2020 \cdot{ }^{13}$

Figure 2. Number of coronavirus disease 2019 (COVID-19) cases according to state, as of June $5,2020 .{ }^{13)}$

cluster. ${ }^{11)}$ This cluster traces itself to a religious gathering (Tabligh) at Jamek Sri Petaling Mosque, Kuala Lumpur held between February 27 and March 2, 2020 and attended by nearly 15 thousand people, including local and international participants. ${ }^{12)}$ During this religious gathering, participants engaged in many activities together, confined to the mosque. Their activities included interacting directly with each other, eating, praying, and sleeping together in the mosque for four consecutive days. The attendees shared many areas, such as toilets, dining areas, and sleeping areas. Although the mosque is large, the number of large attendees made it relatively crowded.

A number of other mass gatherings also occurred in Malaysia in early March 2020, as this was still allowed at the time; however, only the Tabligh gathering led to significant disease transmission, probably due to all the risks explained above. The local attendees were from all states in Malaysia, which resulted in the spread of the virus throughout the country when attendees returned home. The fact that nobody was aware that COVID-19 spread among the Sri Petaling attendees and their close contacts allowed the disease to spread insidiously in the local community throughout Malaysia, including Sabah and Sarawak (Figure 2). ${ }^{13)}$

\section{Early Screening and Detection}

Since the country's Ministry of Health identified the Tabligh event as a potential COVID-19 spreading event, Malaysia has picked up more COVID-19 secondary cases via contact tracing from the Sri Petaling cluster. The control measure for the Sri Petaling cluster was laborious, as the participants of the event were scattered throughout the country. However, with good cooperation with the head of the Tabligh organization and religious councils, contact tracing and active case detection were manageable. As of May 29, 2020, there were 3,370 positive cases out of 41,320 persons screened ( $8.16 \%$ yield); the Sri Petaling cluster has contributed $43.5 \%$ to the total number of COVID-19 cases in Malaysia. $^{13)}$

As for international travelers, all Malaysian citizens who have returned from abroad are quarantined and monitored upon arrival for 14 days. Malaysia has prepared 409 quarantine centers throughout Malaysia capable of accommodating 40 thousand inhabitants at any one time. ${ }^{14)}$ As of May 29, 2020, 44,253 individuals have been quarantined, and 472 positive COVID-19 cases have been identified from the quarantine centers. ${ }^{13)}$ 


\section{Quarantine and the Movement Control Order}

Quarantine is not an ordinary day-to-day health measure in Malaysia; the last time it was widely used was during the H1N1 pandemic in $2009 .{ }^{15)}$ Hence, many of those currently covered by this health measure are experiencing it for the first time. Some of those affected cannot fully understand the quarantine orders and mingle with their family members as usual. Quarantines lead to emotional distress and anxiety for some people, and these psychological responses have also been reported in other countries. ${ }^{16,17)}$ To alleviate this problem, during quarantine, a psychosocial assistant is provided to those in need by the relevant healthcare workers.

Amid the pandemic, many countries across the world including China, India, Italy, and the United Kingdom have relied on lockdowns as a public health and social measure to suppress the spread of COVID-19. ${ }^{18-21)}$ Even so, while millions across the world are confined to their homes, offices and businesses are shut, and economies are on the verge of collapse, Sweden and South Korea have not followed others in locking down their residents. ${ }^{22)}$ In response to the COVID-19 pandemic, South Korea introduced an extensive screening program for early detection and the systematic tracing and quarantine of closecontacts of infected individuals. ${ }^{23)}$ South Korea's screening program has proved to be successful, as its COVID-19 mortality rate is just five per million population. ${ }^{24)}$ In contrast, for Sweden, in the absence of a lockdown, its COVID-19 mortality rate per million population is currently among the top ten highest in the world, at 452 per million population. ${ }^{24)}$

Malaysia implemented a limited lockdown following an exponential rise in COVID-19 cases in March 2020. Lockdown measures have been called different names in different countries, and in Malaysia, such measures were named the Movement Controlled Order (MCO). The MCO was initiated by the government on March 18 as a measure to immediately suppress the spread of COVID-19 (Figure 1). ${ }^{11,13)}$ As enforced under the Control and Prevention of Infectious Diseases Act 1988 and the Police Act 1967, the order defines the following: the complete restriction of movement and assembly nationwide, including religious activities, sports, social and cultural events; a total travel ban of all Malaysian citizens traveling abroad; a complete ban of foreign visitors and tourists into the country; the closure of all primary, secondary, and higher education facilities; and the closure of all government and private premises, except those involved in essential services. If caught red-handed violating these measures without any intention of providing essential services, any person can be jailed or fined, as enforced by the Control and Prevention of Infectious Diseases Act 1988 and the Police Act $1967 .^{25)}$

\section{Risk Stratification Strategy}

Apart from the MCO, the Malaysian government has implemented a risk stratification strategy based on the number of confirmed cases compared with states and districts. The strategy uses a color-coded mechanism, segregating the number of cumulative confirmed cases according to traffic light colors: green means the district does not have any confirmed cases, white means the cases are from one to 19, orange means there are 20 to 40 cases, and red marks the 40-case threshold. As of early May 2020, 27 districts in Malaysia have been classified into red zones at least once. ${ }^{9)}$ To further enhance the risk stratification strategy, it has been improvised from the cumulative case approach to the active case approach. Active cases refer to the total number of cases minus the number of discharged and deceased cases. As shown in Figure $1{ }^{13)}$ all states have reported COVID-19 cases, although the number of cases per state varies widely. As of May 29, five out of 15 states in Malaysia (33.3\%) had been cleared of any active COVID-19 cases. $^{26)}$

In certain localized hotspots, the enhanced MCO (EMCO) is applied when a cluster of cases is found, without setting any threshold number of positive cases in a certain place. The decision to implement the EMCO depends on the National Security Council, with advice from the Ministry of Health Malaysia. The EMCO mimics a total lockdown, in which inhabitants are not allowed to leave their homes. Food supplies and basic amenities are provided by the government. The EMCO allows contact tracing and screening to be carried out more efficiently, resulting in faster and more effective pandemic control. ${ }^{27)}$ As of early May, six localized hotspots have been identified. ${ }^{28)}$

As a whole, the MCO was implemented for more than 6 weeks before it was eased into the Conditional MCO (CMCO) on May 4, 2020. The prime minister announced the shift to the CMCO as being effective until June 9, which has allowed the reopening of certain areas of the economy, free movement, and social activities, except for mass gatherings and interstate traveling. The CMCO received different reactions from various states in Malaysia. Six states (Sabah, Sarawak, Kedah, Penang, Pahang, and Kelantan) initially chose to defer the implementation of the CMCO, pending further study on the state of COVID-19 in their territories. Selangor, the country's most developed state, has largely followed the relaxed CMCO and reopened businesses, prohibiting only dining in at eateries and closing a few public parks despite having the second-highest number of COVID-19 cases in Malaysia (Figure 1). ${ }^{13)}$ Negeri Sembilan, one of Malaysia's states, has also reopened certain economic sectors, but will maintain restrictions on social activities; businesses are not allowed to resume in areas with new coronavirus cases. ${ }^{29)}$

\section{CLINICAL MANAGEMENT RESPONSES TO THE COVID-19 PANDEMIC}

Unlike the public health approach, which is entirely under the public's domain, Malaysia has a dual-tiered system of clinical management services: a government-led sector funded by the public sector and a private sector, creating a dichotomous yet synergistic public-private model. Both sectors have been affected and are involved in managing the COVID-19 pandemic to meet the healthcare needs of the nation. While the public sector manages the inpatient COVID-19 cases, the private sector covers for the spillover cases from government hospitals, and both public and private sector laboratories are extensively utilized 
in screening and diagnostic tests. Collaboration and a specific arrangement have also been implemented between public and private healthcare practitioners, whereby non-COVID-19 cases from government hospitals can be transferred to private hospitals, with private doctors providing clinical services free of charge or "pro bono." This has further eased the burden of public healthcare practitioners in combating COVID-19. ${ }^{30)}$

\section{Adjustment in Hospital Capacity}

At the government hospital level, during the first wave of the outbreak, only a handful of hospitals in Malaysia were identified for diagnosing and treating COVID-19, with one hospital per state. However, as the pandemic progressed, Hospital Sungai Buloh in Selangor has since been converted into the national COVID-19 center, transferring nonCOVID-19 cases to nearby hospitals. ${ }^{31)}$ To date, Malaysia has 118 government hospitals for COVID-19 screening and 40 hospitals for admission and treatment. ${ }^{7}$

To cater to the increased demand for COVID-19 screening, more governmental health facilities have been converted into COVID-19 screening centers. Major changes have been made in emergency department and health clinic settings, where specific "tents" have been built to cater for possible COVID-19 cases. This has been translated into more healthcare staff and areas involved with handling COVID-19 patients, which requires certain guidelines, specially designated areas, and special personal protective equipment (PPE). The lack of PPE, which is very important in preventing disease transmission to healthcare workers, has increased their anxiety, and the limited number of COVID-19 test kits has worsened the situation. Healthcare workers are being asked to work in shifts, while their holidays have been frozen to aggressively fight the pandemic.

At the private hospital level, major modifications have been made in terms of relocation of staff and wards to comply with the isolation protocol for COVID-19 patients and suspects. Specific wards have been designed to cater to potential COVID-19 patients while waiting for laboratory test results. If a patient is confirmed to be negative for COVID-19, the patient will be transferred from the isolation ward to a normal ward. If a patient tests positive, the patient is immediately transferred to a designated COVID-19 government hospital. Drive-through testing services have also been initiated in many private hospitals to accommodate for massive screening approaches by the government. $^{32)}$

\section{Adjustment in Clinical Management}

Since COVID-19 first emerged, the Malaysian guidelines for disease management have been frequently updated to cope with the dynamic nature of the pandemic. The definition of a PUI has been iteratively amended to capture different categories of high-risk individuals. ${ }^{33)}$ At the beginning of the pandemic, the definition of a PUI included only travelers from Wuhan, China. As the pandemic continued to spread, people from other countries and places such as Italy, Korea, Hong Kong, Japan, and Iran were added to the PUI list. Finally, upon the
WHO's announcement of the COVID-19 disease as a pandemic, countries of origin have no longer mattered; anybody with a history of traveling abroad has been considered a PUI. Concurrently, Malaysia is seeing a rise in local cases far exceeding imported cases, which indicates a widespread transmission of the disease occurring in the community.

At the health clinic level, discrepancies between instructions from higher authorities and the constant changes in the definition of a PUI lead to much confusion among healthcare workers, especially among frontline doctors involved in the screening and diagnosis of COVID-19 cases. In response to the rapid need for information, many online webinars have been initiated by the COVID-19 Taskforce and Crisis Preparedness and Response Centre to educate doctors and front liners in understanding and dealing with COVID-19 in a better manner. ${ }^{34)}$ The Malaysian Thoracic Society has also come up with specific guidelines for the inhalational protocol for asthma and chronic obstructive pulmonary disease COVID-19 patients, as it is no longer advisable to rely on nebulizers amid the pandemic. ${ }^{35)}$

In terms of COVID-19 treatment, few antiviral therapies have been used per compassionate use, as many randomized controlled trials for treatment drugs are ongoing. The drugs that are being used in Malaysian COVID-19 hospitals include hydroxychloroquine, chloroquine, remdesivir, ribavirin, interferon beta $1 b$, and Kaletra (lopinavir/ritonavir). Plasma therapy is currently being explored as an avenue for treatment, as per an April 4, 2020 health report. ${ }^{36}$

\section{Adjustment in the Management of Non-COVID-19 Patients} The pandemic has also led to an increase in telemedicine between doctors and patients. During the MCO, non-COVID-19 patients were restricted from attending non-emergency clinic appointments, as many clinics re-scheduled their appointments to prevent further spread of the virus. Patients have also been apprehensive of going to the hospital because of the risk of contracting the virus from the hospital and other high-risk patients. Hence, some government and private hospitals have come up with telemedicine as a medium for health practitioners to see their patients via a "virtual clinic" at the comfort of the patient's home.

This facility has been found to be useful among non-critical patients who need to review their medications and follow up with their respective doctors and who do not need a thorough physical examination and extensive investigation. The facility has also been found to help alleviate patients' anxiety and address their health concerns, especially pertaining to COVID-19 and their diseases. Certain specialties that require much communication between doctors and patients have benefited from this program, especially psychiatry. However, among the pitfalls of telemedicine, it is not suitable for certain diseases that require specific and thorough examinations, such as ophthalmology, neurology, cardiology, gastroenterology, and other surgical-based conditions. For essential medical conditions that require physical hospital visits, the seats and tables of consultation clinics have to be arranged at one-meter distances as per Malaysian National Security 
Council recommendations.

\section{Laboratory Capacity for Diagnostic Tests}

In terms of diagnostic tests, the RT-PCR test is the gold standard for diagnosing COVID-19 and is widely used globally because of its high accuracy rate. A swab is taken from either an individual's nasopharyngeal or oropharyngeal area, and the RT-PCR laboratory procedure usually takes 24 hours to complete. In the initial stage of the pandemic, the IMR was the only laboratory involved in diagnosing COVID-19, but capacity has since been expanded and strengthened to include 44 laboratories from the public, universities, and the private sector to meet demands. Malaysia's testing capacity for COVID-19, which currently stands at 11,500 samples per day, is expected to increase with the expected addition of five new laboratories. ${ }^{33,37)}$ These five facilities will be located in Tawau, Sandakan, Miri, Bintulu, and Kluang; soon, there will be 48 testing facilities nationwide. The ministry has targeted the achievement of 16,500 tests per day by mid-April. ${ }^{38)}$

As of March 2020, the use of a faster antigen-based rapid test kit has not been endorsed owing to its low sensitivity. Thus, reliance with regard to tests is still on the RT-PCR test, resulting in a bottleneck scenario and a lag in diagnosing capacity. The delay in achieving a confirmed case result has been obvious, as reflected by the high number of daily pending results. The Ministry of Health Malaysia has conducted COVID-19 screenings on 126,970 people as of April 25, 2020, which translates to four per thousand people. ${ }^{39)}$ The WHO has set $10 \%$ as a suitable limit for a country's screening capacity. A recent circular from Ministry of Health Malaysia recommended the use of the Antigen Rapid Test Kit (RTK-Ag) for rapid point-of-care testing, which can be performed rapidly and on a large scale. ${ }^{40)}$ This test kit has passed the IMR's evaluation, with a sensitivity of $84.4 \%$ and a specificity of $100 \%$, and its price is also cheaper compared with the usual RT-PCR test. The indications for the RTK-Ag are listed as follow: (1) preoperative testing for emergency and semi-emergency cases involving patients with a high risk of COVID-19 infection; (2) screening for patients with ILI; (3) screening for cases "brought in dead" with a high possibility of a COVID-19 infection; (4) massive screening for cases within EMCO areas; and (5) screening at the Malaysian border, especially for transit passengers to Sabah and Sarawak.

Figure 3 shows that by the end of April, the Ministry of Health achieved the target of 16,500 tests per day, and by mid-May, laboratory capacity reached 30,000 tests per day with the help of private laboratories. $^{7,13)}$

\section{COMMUNITY EMPOWERMENT AND INTER-AGENCY APPROACH}

COVID-19 easily spreads from one person to another by means of respiratory droplets and, to a certain extent, through fomites, entering the body when a contaminated hand touches the eye, mouth, or nose. ${ }^{41)}$ Therefore, to prevent transmission, direct human interaction and restriction of movement by means of isolation, quarantines, and social distancing measures should be enforced. The community is educated and empowered to synergize the effectiveness of the MCO. Coordinated information campaigns were carried out throughout the lockdown period to prepare communities for new norms as the government eased on lockdown restrictions (Figures 4, 5). ${ }^{13)}$

Malaysia is now in the phase of adjusting in all settings following the ease of the MCO to the CMCO, in which most of the country's workforce has resumed their work under strict preventive measures called new norms. New norms include avoiding the 3Cs (close conversations, confined spaces, and crowded places) and practicing the 3Ws (washing hands, wearing masks, and following warnings, e.g., beware of COVID-19). At the community level, extensive and continuous health education and promotion have focused on the individual, emphasizing staying at home and proper handwashing, using soap or hand sanitizers. If staying at home is not possible, social distancing at least one meter apart is necessary. People are also advised to wear face masks whenever they are in public places. ${ }^{42)}$ Each community member is expected to play a role in preventing resurgence in case numbers.

Awareness regarding the lack of PPE and medical instruments has also been high among Malaysians, which has led to many donation drives, initiated by royalty, non-government organizations (NGOs),

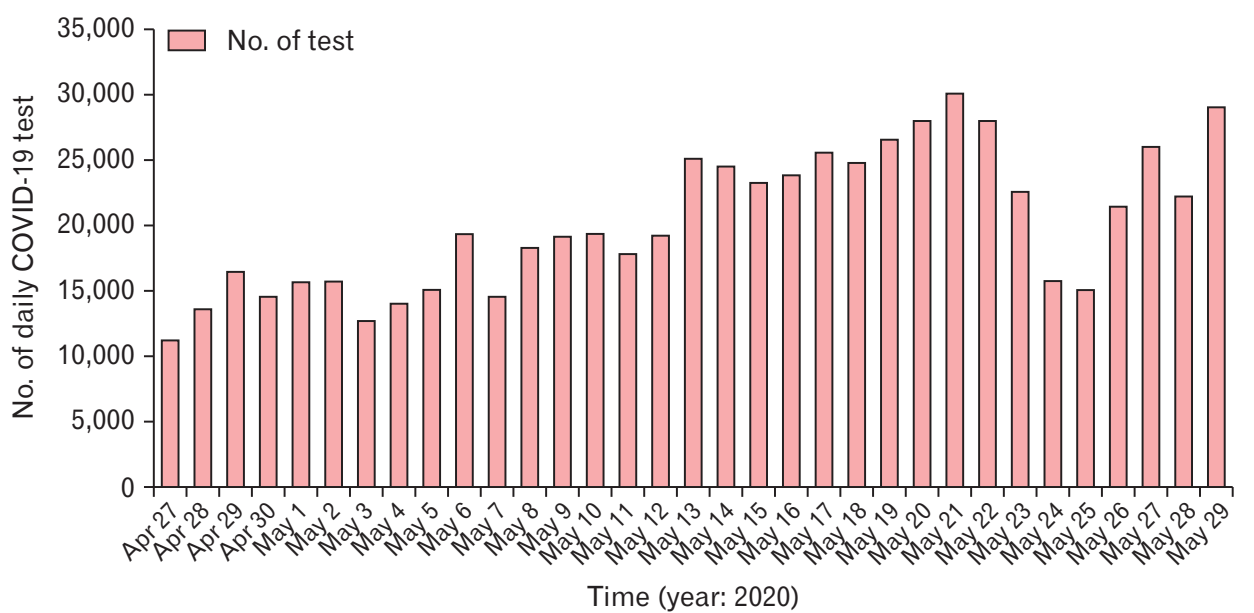

Time (year: 2020)
Figure 3. Number of daily coronavirus disease 2019 (COVID-19) test in Malaysia as of May $29,2020 .^{13)}$ 

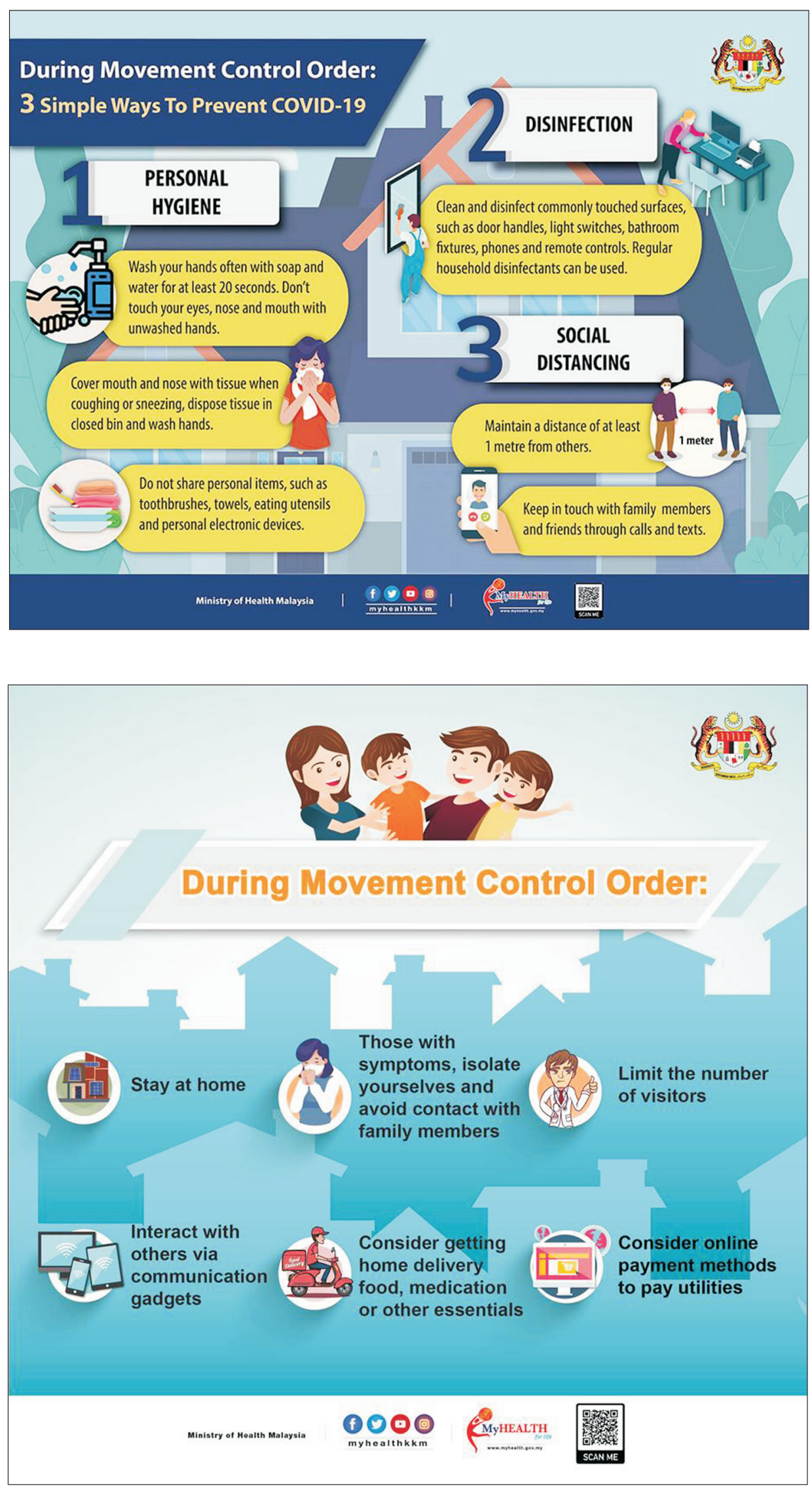

Figure 4. Educational poster regarding coronavirus disease 2019 (COVID-19) prevention during Movement Control Order (MCO) implementation by Malaysian National Security Council. ${ }^{13)}$
Figure 5. Educational poster regarding advice during Movement Control Order (MCO) implementation by Malaysian National Security Council. ${ }^{13)}$ 
universities, corporate entities, and medical societies. ${ }^{43)}$ Aside from PPE, donations have also included financial support and technical support tools such as tents, air-conditioners, air purifiers, and thermal scanners, as well as disposable hijabs for female Muslim healthcare workers, and these initiatives have lifted some healthcare burdens. ${ }^{44)}$ The Malaysian queen has donated 100 beds to Hospital Sungai Buloh and 50 beds to Hospital Kuala Lumpur, ${ }^{45)}$ and the Sultan of Johor has donated 42 ventilators to Ministry of Health Malaysia. ${ }^{46)}$ Malaysian public and private universities have supported the provision of face shields, PPEs, and intubation box prototypes for medical frontlines throughout the country. ${ }^{47}$ The Malaysian Health Coalition, which comprises all Malaysian medical societies, health-related NGOs, and influential medical personnel throughout the country, has been proposing ideas and strategies to combat COVID-19 effectively. ${ }^{47)}$

Apart from healthcare, other sectors such as education, engineering, and information technology are involved in fighting COVID-19. Artificial intelligence and the usage of big data and data-driven countermeasures have proved to be significant in helping combat the pandemic. In this regard, two mobile applications-MySejahtera and MyTrace-have been produced. MySejahtera enables people to perform self-health assessments and aid Ministry of Health Malaysia to garner early information for control and prevention procedures. The function of hotspot tracking permits users to obtain information on COVID-19 hotspot areas by a 1-kilometer radius from the user's home address. In addition, MySejahtera provides information on the nearest COVID-19 screening facility and online health advice. Meanwhile, MyTrace helps with contact tracing and complements MySejahtera. Both applications come without any implied charges. ${ }^{48)}$

\section{RECOVERY PHASE OF THE COVID-19 PANDEMIC IN MALAYSIA}

COVID-19 is unprecedented. Never has a pandemic of this scale and severity occurred in recent years. The entire world is fighting a pandemic more severe than the 1918 pandemic, which killed approximately 20 to 40 million people worldwide. ${ }^{49)}$ The main goal of COV-
ID-19 public health strategies to suppress transmission and reduce mortality has largely been achieved through the implementation of large-scale public health and social measures. Since a vaccine or cure for COVID-19 has yet to be identified in May 2020, the importance of these traditional public health measures has greatly been evident.

As of the time of writing (May 30, 2020), Malaysia has experienced two COVID-19 waves (Figure 1), ${ }^{13)}$ the latter of which was bigger and persisted for more than 2 months, resulting in 7,732 cases with 115 deaths (1.5\%). Malaysia has passed the peak of the curve, and $80.64 \%$ of confirmed cases have recovered (Figure 6). ${ }^{13)}$ The highest number of hospitalized patients was 4,326 on April 5 (Figure 6), ${ }^{13)}$ leaving a remaining 2,595 available beds. The maximum bed capacity of COVID-19 hospitals is 6,291 beds. ${ }^{28)}$ Malaysia has successfully provided optimum care for all confirmed COVID-19 patients, irrespective of the degree of their symptoms, and most quarantine processes have been conducted in a socially acceptable manner. The fact that Malaysia's healthcare system has not been overwhelmed excessively during this

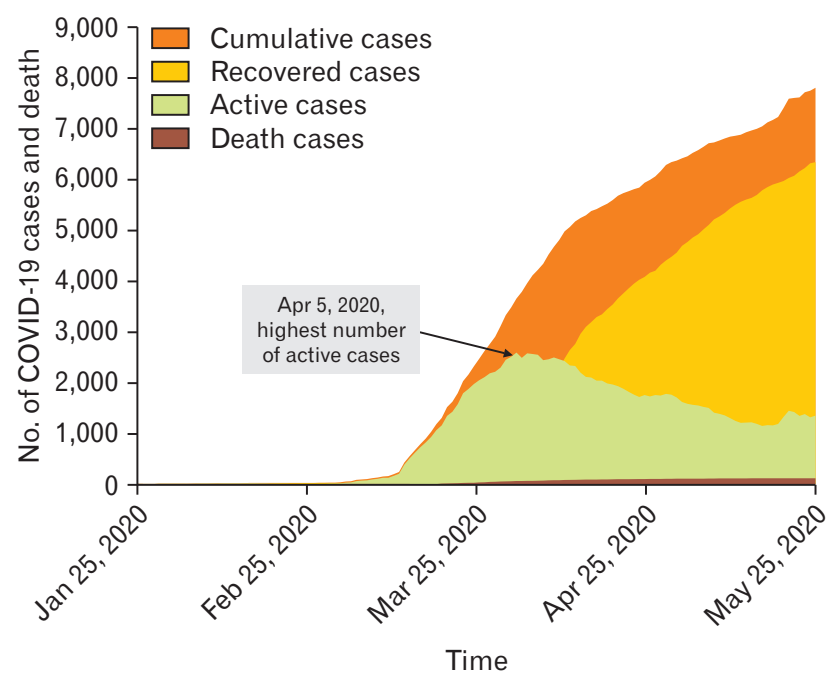

Figure 6. Number of cumulative, recovered, and active coronavirus disease 2019 (COVID-19) cases and death in Malaysia, 2020. ${ }^{13)}$

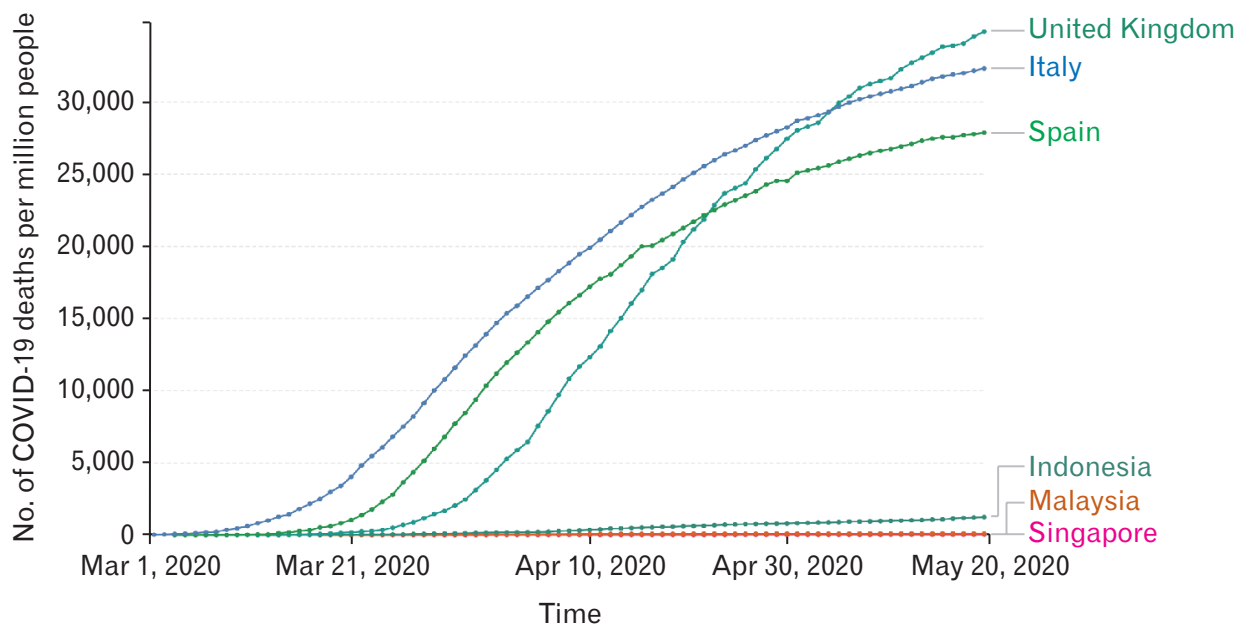

Figure 7. Total confirmed coronavirus disease 2019 (COVID-19) deaths per million people. Limited testing and challenges in the attribution of the cause of death means that the number of confirmed deaths may not be an accurate count of the true total number of deaths from COVID-19. ${ }^{13,39}$ 
large second wave has been a great relief to everyone. As of the time of writing, the MCO has been implemented for more than 6 weeks. This 6 -week duration is crucial, as it buys some time for the healthcare system to gradually increase its capacity and allows healthcare staff to gain important experience in dealing with the pandemic. All this experience has prepared them emotionally and physically if further waves are going to recur, as predicted by the WHO.

At the end of May, it was obvious that COVID-19's mortality rate in Malaysia would not follow the rate in Italy (Figure 7). ${ }^{13,39)}$ This fact eased tensions and reduced the fear felt by all Malaysians. The current COVID-19 mortality rate in Malaysia is three per million people, which is far below the mortality rate in Italy, Spain, and the United Kingdom, where the rate is about 400 to 500 per million people. ${ }^{24)}$ Malaysia has a similar mortality rate to its neighboring countries, Singapore and Indonesia. Although Malaysia was the first country in Southeast Asia that showed an exponential rise in COVID-19 cases in March and the first Association of Southeast Asian Nations country to reach 1,000 cases, Singapore, Indonesia, and the Philippines have since surpassed Malaysia. The Malaysian healthcare has responded well to the COVID-19 pandemic.

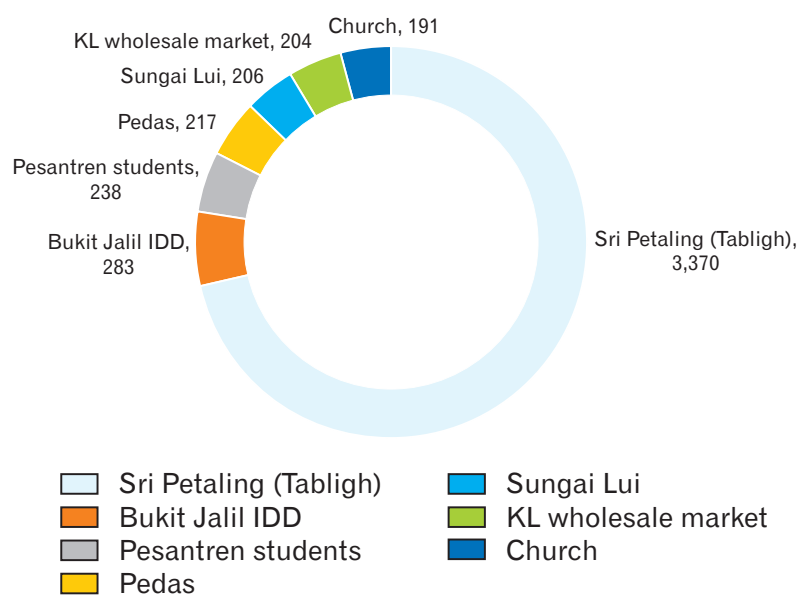

Figure 8. Number of coronavirus disease 2019 cases in Malaysia by major cluster as of May 29, 2020. ${ }^{13)}$

\section{CHALLENGES IN COMBATTING THE COVID-19 PANDEMIC IN MALAYSIA}

After extensive public health and social measures, Malaysia has managed to reduce the number of active COVID-19 cases nationwide, and the situation in the country has become more manageable (Figure 6). ${ }^{13)}$ The Ministry of Health has managed to detect many clusters and further identified a vulnerable group that had a higher risk of contracting COVID-19. As of May 29, 2020, the largest cluster in Malaysia has been the Sri Petaling (Tabligh) cluster, with 3,370 cases (Figure 8). ${ }^{13)}$ Other clusters have been relatively smaller, with no more than 300 cases for each cluster (Figure 9). ${ }^{13)}$ The Bukit Jalil IDD cluster included undocumented foreign workers detained by Malaysian immigration. Pesantren students refer to Malaysian students who study in Islamic boarding schools in Indonesian who returned home to Malaysia. The number of cases and rate of mortality in Indonesia have been far higher than in Malaysia; thus, it is expected that Malaysian students returning home from Indonesia would have a higher chance of testing positive for COVID-19.

Figure 9 shows that 205 out of 217 people in the Pedas cluster and 145 out of 204 persons in the Kuala Lumpur wholesale market cluster were migrant workers. ${ }^{13)}$ Currently, the pattern of clusters in Malaysia is quite similar to Singapore, where COVID-19 clusters have particularly occurred among migrant workers, especially among the lowskilled, who tend to live in overcrowded and unsanitary conditions,

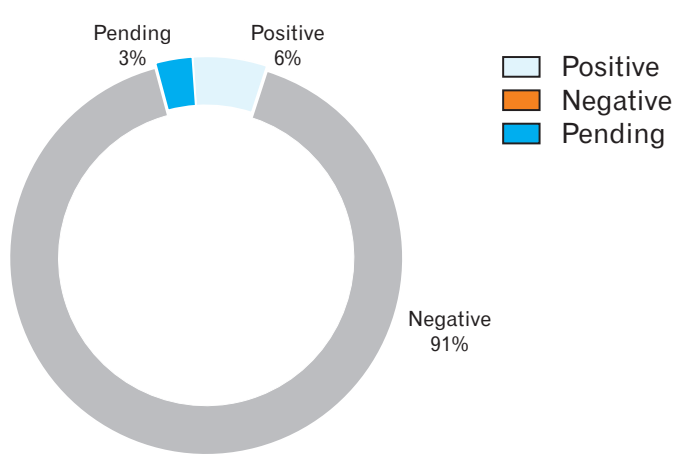

Figure 10. Number of non-Malaysians screened for coronavirus disease 2019 $(n=31,204)$ as of May $28,2020(N=31,204){ }^{13)}$

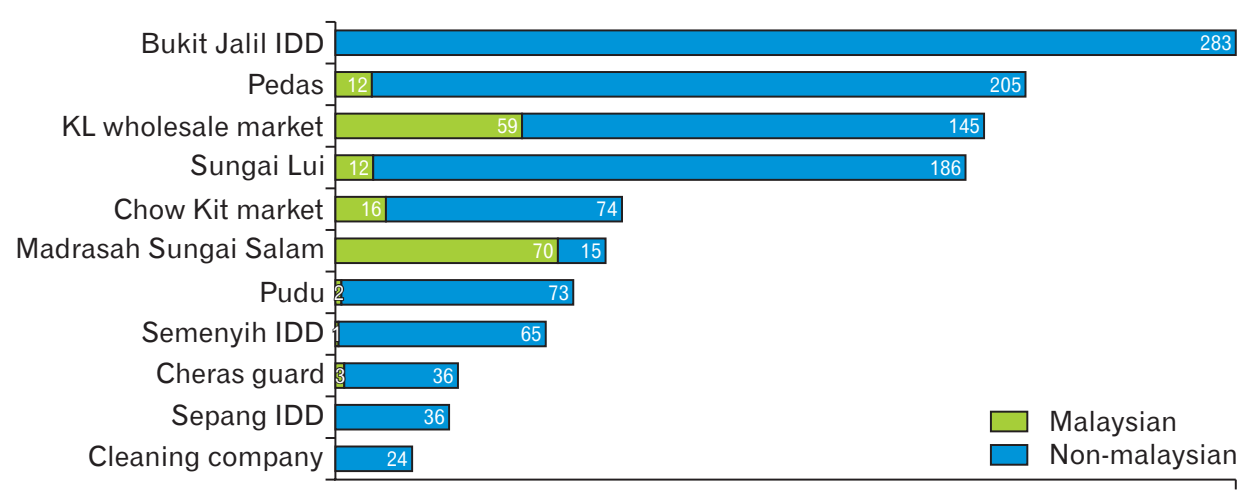

Figure 9. Major coronavirus disease 2019 clusters in Malaysia involving non-Malaysians as of May 29, 2020. ${ }^{13)}$ 
which increase their risk of contracting and transmitting the disease. Currently, the Ministry of Health Malaysia continues to actively screen migrant workers (Figure 10). ${ }^{13)}$ Between 2010 and 2017, the number of documented migrant workers in Malaysia increased from 1.7 to 2.2 million, and as of the end of 2018, there are an estimated 2 to 4 million additional undocumented migrant workers in Malaysia. ${ }^{50)}$ Major countries of origin of migrant workers include Indonesia, Nepal, Bangladesh, India, and Myanmar, and a smaller number of workers come from other Asian countries. There are 163,000 refugees and asylum seekers in Malaysia registered with the United Nations High Commissioner for Refugees, including 142,000 from Myanmar and the remaining 21,890 from other countries and areas, including Pakistan, Yemen, Somalia, Syria, Sri Lanka, Afghanistan, Iraq, and the Palestinian Territories. ${ }^{50)}$ This huge number of migrant workers from various backgrounds is a real challenge for the Malaysian healthcare system in combatting the COVID-19 pandemic as it not easy to locate all of these individuals; there may also be the issue of a language barrier.

Malaysia has become a popular destination for migrant workers from neighboring lower-income countries, owing to its fast and stable economic progress. The migrant workforce has been floating around $15 \%$ of the total labor force in recent years according to Labour Force Surveys by the Department of Statistics Malaysia, ${ }^{51)}$ as reported by the World Bank ${ }^{50)}$ in 2019 in their report, "Malaysia-estimating the number of foreign workers." Most migrant workers in Malaysia tend to be low-skilled; work in labor-intensive sectors such as the manufacturing, construction, plantation, agriculture, and domestic helper sectors; and reside in Sabah, Selangor, and Johor, similar to the pattern of COVID-19 cases found that involve low-skilled sectors during COVID-19 outbreak in Singapore, April 2020.52) Indonesians continue to be Malaysia's dominant foreign worker group, benefiting from geographical and cultural proximity, and the fact that Indonesia is currently experiencing a high COVID-19 mortality is a reflection of the country's poor health response to COVID-19, further increasing the risk for Malaysia due to the issue of migrant workers. The issue of COVID-19 clusters among migrant workers is handled through an inter-agency approach by the Ministry of Health, the Immigration Department, and other relevant agencies.

Unfortunately, the imposed MCO in Malaysia has had an adverse economic impact. The Report of Malaysia Economic Performance First Quarter 2020 from the Department of Statistics Malaysia shows that Malaysia's gross domestic product grew by $0.7 \%$ from $3.6 \%$ in the fourth quarter of 2019. This is the lowest growth recorded since the third quarter of 2009 at $-1.1 \%$. The growth in this quarter was provided by the services sector (3.1\%) and the manufacturing sector (1.5\%), while the other economic sectors reported negative growth. With fears of an economic recession and financial collapse, times like these call for resilient and strong leadership not just in healthcare but also in business, government, and the Malaysian community as a whole. The government has responded to such fears by announcing an economic stimulus plan to weather the difficult period. Immediate relief measures are planned and adjusted for those that may fall through the cracks. Medium- and long-term planning is needed to re-balance and re-energize the economy following the crisis.

The MCO in Malaysia has also had a negative social impact. In the United Kingdom, lockdown and social distancing measures to prevent the spread of COVID-19 have heightened fear of increasing levels of domestic violence, including physical, emotional, and sexual abuse. ${ }^{53}$ Similarly, in Malaysia, the Women's Aid Organization has released statistics showing an increased trend of violence at home. Between February and March, WhatsApp and short message service helplines experienced an approximately $42 \%$ increase in enquiries, and a $50 \%$ increase in phone calls. ${ }^{54)}$ In this aspect, the Ministry of Women and the Welfare Department are playing their part, although they may have not maximized their potentials and much improvement is needed. In addition, a significant impact of the COVID-19 pandemic has been observed within the video and gaming industry. Furthermore, according to the internet pornography website Pornhub, Malaysia ranked as the top Asian country with the most visits during the period of the MCO implementation. ${ }^{55)}$ According to Pornhub's soaring traffic, the statistics show that Malaysia reached fourth place (84\%) overall during the MCO period. Thus, MCO could have an impact on the psychological well-being of the nation.

\section{CONCLUSION}

Modernization and the expansion of the aviation industry render human interactions to occur at an unbelievable speed, and within 4 months of COVID-19's emergence, almost all countries around the world have been affected. As a result, we witnessed the birth of the coronavirus pandemic at an exponential rate beyond the capacity of many healthcare systems. At the global level, the world is still dealing with COVID-19 at an early stage of the pandemic. Preparations have been made amid people not fully understanding the virus. There are still many unknown factors associated with this novel coronavirus, yet the pandemic continues. Hence, we are far from seeing the impact of COVID-19 in its totality. The obvious learning points for the healthcare system in managing the pandemic are as follows:

First, early and timely decisions are crucial to curb the spread of the outbreak, even if it may mean temporarily compromising other important sectors, such as the economy and education system. Second, the importance of well-coordinated response teams led by the highest government authority in ensuring preventive and clinical domains can be optimally utilized from both the public and private sectors. Third, the spillover effect of the economic recession has an effect on the economic and social ill health, as the reported cases of domestic violence and the number of viewers on pornography websites increased during the MCO period. Thus, the fourth point is to always have an interagency, inter-ministry approach to ensure that all pockets of community needs can be reached as much as possible. The COVID-19 pandemic has changed many aspects of Malaysia's life, from health to the economy, to socio-politics. We are still learning to adapt to new norms in our daily lives. Further quantitative (epidemiological) and qualita- 
tive (social) research is needed to explore the impact of COVID-19 on Malaysian society and to further understand this novel disease.

\section{CONFLICT OF INTEREST}

No potential conflict of interest relevant to this article was reported.

\section{ORCID}

Safiya Amaran: https://orcid.org/0000-0003-4856-1811

Ahmad Zulfahmi Mohd Kamaruzaman:

https://orcid.org/0000-0001-5951-4979

Nurul Yaqeen Mohd Esa: https://orcid.org/0000-0002-9284-1282

Zaharah Sulaiman: https://orcid.org/0000-0002-4023-1845

\section{REFERENCES}

1. Aylward B, Wannian L. Report of the WHO-China Joint Mission on coronavirus disease 2019 (COVID-19) [Internet]. Geneva: World Health Organization; 2020 [cited 2020 Apr 14]. Available from: https:// www.who.int/docs/default-source/coronaviruse/who-china-jointmission-on-covid-19-final-report.pdf.

2. Huang C, Wang Y, Li X, Ren L, Zhao J, Hu Y, et al. Clinical features of patients infected with 2019 novel coronavirus in Wuhan, China. Lancet 2020;395:497-506.

3. Kang D. The shunned: people from virus-hit city tracked, quarantined. AP NEWS [Internet]. 2020 Feb 1 [cited 2020 Apr 14]. Available from: https://apnews.com/7f7336d2ed099936bd59bf8cb7f43756.

4. Lu D. Inside Wuhan's lockdown. New Sci 2020;245:7.

5. Xinhua. All 16 temporary hospitals in Wuhan closed. Xinhua [Internet]. 2020 Mar 10 [cited 2020 Apr 14]. Available from: http://www.xinhuanet.com/english/2020-03/10/c_138863160.htm.

6. The Malay Reserve. Coronavirus: more thermal scanners to be placed at entry points into Malaysia. The Malay Reserve [Internet]. 2020 Jan 27 [cited 2020 May 10]. Available from: https://themalaysianreserve. com/2020/01/27/coronavirus-more-thermal-scanners-to-be-placedat-entry-points-into-malaysia/.

7. Ministry of Health of Malaysia. KPK press statement 26 April 2020: current situation of coronavirus infection 2019 (COVID-19) in Malaysia [Internet]. Putrajaya: Ministry of Health of Malaysia; 2020 [cited 2020 May 10]. Available from: https://kpkesihatan.com/2020/04/26/ kenyataan-akhbar-kpk-26-april-2020-situasi-semasa-jangkitan-penyakit-coronavirus-2019-covid-19-di-malaysia/.

8. Salim N, Chan WH, Mansor S, Bazin NE, Amaran S, Mohd Faudzi AA, et al. COVID-19 epidemic in Malaysia: impact of lockdown on infection dynamics [Internet]. Laurel Hollow (NY): medRxiv; 2020 [cited 2020 Apr 14]. Available from: https://doi.org/10.1101/2020.04.08.20057463.

9. Ministry of Health of Malaysia. Malaysia COVID-19 management guidelines No.5/2020. Putrajaya: Ministry of Health of Malaysia; 2020.

10. Ministry of Health of Malaysia. Malaysia influenza surveillance protocol. Putrajaya: Ministry of Health of Malaysia; 2015.

11. Arumugam T. First sporadic COVID-19 case in Malaysia. New Straits Times [Internet]. 2020 Mar 12 [cited 2020 May 10]. Available from: https://www.nst.com.my/news/nation/2020/03/573951/first-sporadic-covid-19-case-malaysia.

12. Ng K. Coronavirus: Malaysia cases rise by 190 after mosque event as imams urge online services. The Independent [Internet]. 2020 Mar 16 [cited 2020 May 30]. Available from: https://www.independent.co.uk/ news/world/asia/coronavirus-malaysia-cases-southeast-asiamosque-islam-a9403816.html.

13. Ministry of Health of Malaysia. KPK press statement 30 May 2020: current situation of coronavirus infection 2019 (COVID-19) in Malaysia [Internet]. Putrajaya: Ministry of Health of Malaysia; 2020 [cited 2020 May 30]. Available from: https://kpkesihatan.com/2020/05/30/kenyataan-akhbar-kpk-30-mei-2020-situasi-semasa-jangkitan-penyakit-coronavirus-2019-covid-19-di-malaysia/.

14. Radzi R. 40,000 Could be quarantined at one time once all 409 centres across Malaysia is ready, says Ismail Sabri. Yahoo! News [Internet]. 2020 Apr 4 [cited 2020 May 10]. Available from: https://malaysia.news. yahoo.com/40-000-could-quarantined-one-070416557.html.

15. Sam IC, Abu Bakar S. Pandemic influenza A (H1N1) 2009 in Malaysia: the next phase. Med J Malaysia 2009;64:105-7.

16. Brooks SK, Webster RK, Smith LE, Woodland L, Wessely S, Greenberg $\mathrm{N}$, et al. The psychological impact of quarantine and how to reduce it: rapid review of the evidence. Lancet 2020;395:912-20.

17. Wang C, Pan R, Wan X, Tan Y, Xu L, Ho CS, et al. Immediate psychological responses and associated factors during the initial stage of the 2019 coronavirus disease (COVID-19) epidemic among the general population in China. Int J Environ Res Public Health 2020;17:1729.

18. Lau H, Khosrawipour V, Kocbach P, Mikolajczyk A, Schubert J, Bania J, et al. The positive impact of lockdown in Wuhan on containing the COVID-19 outbreak in China. J Travel Med 2020;27:taaa037.

19. Thornton J. Covid-19: A\&E visits in England fall by $25 \%$ in week after lockdown. BMJ 2020;369:m1401.

20. Pulla P. Covid-19: India imposes lockdown for 21 days and cases rise. BMJ 2020;368:m1251.

21. Lavezzo E, Franchin E, Ciavarella C, Cuomo-Dannenburg G, Barzon L, Del Vecchio C, et al. Suppression of COVID-19 outbreak in the municipality of Vo,' Italy [Internet]. [place unknown]: MedRxiv; 2020 [cited 2020 May 5]. Available from: https://doi.org/10.1038/s41586-0202488-1.

22. Fisher D, Wilder-Smith A. The global community needs to swiftly ramp up the response to contain COVID-19. Lancet 2020;395:1109-10.

23. Normile D. Coronavirus cases have dropped sharply in South Korea: what is the secret to its success? Science [Internet]. 2020 Mar 17 [cited 2020 Apr 14]. Available from: https://www.sciencemag.org/ news/2020/03/coronavirus-cases-have-dropped-sharply-south-korea-whats-secret-its-success.

24. Worldometer. COVID-19 coronavirus pandemic: coronavirus cases [Internet]. [place unknown]: Worldometer; 2020 [cited 2020 May 5]. Available from: https://www.worldometers.info/coronavirus/.

25. Prime Minister Office. The Prime Minister's special message on COVID-19 [Internet]. Putrajaya: Prime Minister Office; 2020 [cited 2020 May 10]. Available from: https://covid-19.moh.gov.my/terkini/ 032020/situasi-terkini-16-mac-2020/PERUTUSAN\%20KHAS\%20 YAB\%20PM\%20-\%2016032020\%20-\%20final.pdf.pdf.pdf.

26. Ministry of Health of Malaysia. Confirmed COVID-19 cases according to states and districts. Putrajaya: Ministry of Health of Malaysia; 2020. 
27. Ministry of Health of Malaysia. COVID-19 Malaysia [Internet]. Putrajaya: Ministry of Health of Malaysia; c2021 [cited 2021 Jan 23]. Available from: https://covid-19.moh.gov.my/faqsop/sop-perintah-kawalanpergerakan-diperketatkan-pkpd-emco.

28. Kini News Lab. Covid-19 in Malaysia [Internet]. [place unknown]: Kini News Lab; 2020 [cited 2020 May 11]. Available from: https://newslab. malaysiakini.com/covid-19/en.

29. Jun SW. Movement control order not a lockdown, says former health minister. The Malay Mail [Internet]. 2020 Mar 17 [cited 2020 May 10]. Available from: https://www.malaymail.com/news/malaysia/2020/ 03/17/movement-control-order-not-a-lockdown-says-former-healthminister/1847232.

30. Augustin R. We are willing to help, private hospitals tell health ministry. Free Malaysia Today [Internet]. 2020 Mar 21 [cited 2020 Apr 12]. Available from: https://www.freemalaysiatoday.com/category/nation/2020/03/21/were-willing-to-help-private-hospitals-tell-healthministry/.

31. Bernama. Sungai Buloh Hospital to become centre for infectious diseases. Free Malaysia Today [Internet]. 2020 Mar 10 [cited 2020 Apr 12]. Available from: https://www.freemalaysiatoday.com/category/nation/2020/03/10/sungai-buloh-hospital-to-become-centre-for-infectious-diseases/.

32. Birruntha S. Private hospitals have been of service to govt in combating COVID-19. The Malaysian Reserve [Internet]. 2020 Mar 26 [cited 2020 Apr 12]. Available from: https://themalaysianreserve.com/2020/ $03 / 26 /$ private-hospitals-have-been-of-service-to-govt-in-combatingcovid-19/.

33. Ministry of Health of Malaysia. Garis Panduan Pengurusan COVID-19 di Malaysia No.5/2020 [COVID-19 management guidelines in Malaysia No.5/2020] [Internet]. Putrajaya: Ministry of Health of Malaysia; 2020 [cited 2020 Apr 14]. Available from: https://covid-19.moh.gov. my/garis-panduan/garis-panduan-kkm.

34. Ramzdhan M. Dua Cara Utama 2019-nCoV tersebar: Haiwan Ke Manusia vs Manusia Ke Manusia [The two main ways 2019-nCoV are spread: animals humans vs humans human] [Internet]. [place unknown]: DoctorOnCall; 2020 [cited 2020 Apr 14]. Available from: https://www.doctoroncall.com.my/pengenalan-coronavirus/penyebaran.

35. The Malaysian Thoracic Society. The Malaysian Thoracic Society recommendations on inhalational therapy during the COVID-19 pandemic [Internet]. Kuala Lumpur: The Malaysian Thoracic Society; 2020 [cited 2020 Apr 14]. Available from: http://mts.org.my/download/MTS_Recommendations_on_Inhalational_Therapy_During COVID19_Pandemic.pdf.

36. Halid S. UDA Holdings COVID-19 survivor joins pandemic fight, donates blood plasma. New Straits Times [Internet]. 2020 Apr 4 [cited 2020 Apr 12]. Available from: https://www.nst.com.my/news/nation/2020/04/581268/uda-holdings-covid-19-survivor-joins-pandemic-fight-donates-blood-plasma.

37. The Star. COVID-19: Malaysia to receive new test kit from South Korea. The Star [Internet]. 2020 Apr 5 [cited 2020 Apr 12]. Available from: https://www.thestar.com.my/news/nation/2020/04/05/covid-19-malaysia-to-receive-new-test-kit-from-south-korea.

38. Zainul E. Malaysia has yet to achieve target of conducting 16,500 COVID-19 tests per day. The Edge Market [Internet]. 2020 Apr 14 [cited 2020
Apr 15]. Available from: https://www.theedgemarkets.com/article/ malaysia-has-yet-achieve-target-conducting-16500-covid19-tests-day. 39. Our World in Data [Internet]. Oxford: Our World in Data, University of Oxford; 2020 [cited 2020 Apr 12]. Available from: https://ourworldindata.org/.

40. Ministry of Health of Malaysia. Coronavirus disease 2019. Putrajaya: Ministry of Health of Malaysia, Health Education Division; 2020.

41. World Health Organization. Coronavirus disease (COVID-19) pandemic [Internet]. Geneva: World Health Organization; 2020 [cited 2020 Apr 14]. Available from: https://www.who.int/emergencies/diseases/novel-coronavirus-2019.

42. Ministry of Health of Malaysia. COVID-19: social distancing guidelines for workplace, home and individuals [Internet]. Putrajaya: Ministry of Health of Malaysia; 2020 [cited 2020 Apr 24]. Available from: https:// www.moh.gov.my/moh/resources/Penerbitan/Garis\%20Panduan/ COVID19/Annex_26_COVID_guide_for_Social_Distancing_24032020. pdf.

43. The Star. Full backing for our frontliners. The Star [Internet]. 2020 Apr 12 [cited 2020 Apr 14]. Available from: https://www.thestar.com.my/ news/education/2020/04/12/full-backing-for-our-frontliners.

44. Chai J. We verified $21 \mathrm{M}$ 'sian fundraisers you can donate to in support of COVID-19 relief efforts. Vulcan Post [Internet]. 2020 Mar 25 [cited 2020 Apr 12]. Available from: https://vulcanpost.com/693014/covid19-charity-donation-malaysia-food-medical-supplies/.

45. Rahim R. Queen donates 100 beds to Sungai Buloh Hospital, 50 to Kuala Lumpur Hospital. The Star [Internet]. 2020 Apr 12 [cited 2020 Apr 14]. Available from: https://www.thestar.com.my/news/nation/2020/04/12/queen-donates-100-beds-to-sungai-buloh-hospital50-to-kuala-lumpur-hospital.

46. Shah MF. Johor Sultan donates 42 ventilators to hospital in the state. The Star [Internet]. 2020 Apr 11 [cited 2020 Apr 14]. Available from: https://www.thestar.com.my/news/nation/2020/04/11/johor-sultandonates-42-ventilators-to-hospital-in-the-state.

47. Chan D. Health coalition recommends increased COVID-19 testing capacity. New Straits Times [Internet]. 2020 Apr 11 [cited 2020 Apr 14]. Available from: https://www.nst.com.my/news/nation/2020/04/583345/ health-coalition-recommends-increased-covid-19-testing-capacity.

48. Ministry of Health of Malaysia. COVID-19 Malaysia: FAQ UMJUM [Internet]. Putrajaya: Ministry of Health of Malaysia; 2020 [cited 2021 Jan 23]. Available from: https://covid-19.moh.gov.my/faqsop/mysejahtera.

49. Mills CE, Robins JM, Lipsitch M. Transmissibility of 1918 pandemic influenza. Nature 2004;432:904-6.

50. World Bank. Malaysia: estimating the number of foreign workers: a report from the labor market data for Monetary Policy Task [Internet]. Washington (DC): World Bank; 2019 [cited 2020 May 30]. Available from: http://documents.worldbank.org/curated/pt/953091562223517841/ Malaysia-Estimating-the-Number-of-Foreign-Workers-A-Reportfrom-the-Labor-Market-Data-for-Monetary-Policy-Task.

51. Department of Statistic Malaysia. Malaysia economic performance first quarter 2020 [Internet]. Putrajaya: Department of Statistic Malaysia; 2020 [cited 2020 May 31]. Available from: https://www.dosm.gov. my/vl/index.php?r=column/cthemeByCat\&cat=100\&bul_id=R09wd GZSektvNmw5T1VCeVphNXRqdz09\&menu_id=TE5CRUZCblh4ZTZ MODZIbmk2aWRRQT09]. 
52. Heijmans P, Ngui Y, Thanthong-Knight R. Economics: migrant workers making COVID gear most vulnerable in pandemic. Bloomberg [Internet]. 2021 Jan 23 [cited 2021 Jan 23]. Available from: https://www. bloomberg.com/news/articles/2021-01-22/migrant-workers-porousborders-mar-southeast-asia-recovery.

53. Kelly J, Morgan T. Coronavirus: domestic abuse calls up 25\% since lockdown, charity says. BBC News [Internet]. 2020 Apr 6 [cited 2020 Apr 7]. Available from: https://www.bbc.co.uk/news/uk-52157620.

54. Bernama. WAO: domestic violence calls rise during MCO; more shel- ters needed. New Straits Times [Internet]. 2020 May 5 [cited 2020 May 30]. Available from: https://www.nst.com.my/news/crimecourts/2020/05/589944/wao-domestic-violence-calls-rise-duringmco-more-shelters-needed.

55. Syahrul R. PornHub: Malaysia tops Asian countries with most visits during movement control order. Hype [Internet]. 2020 Mar 22 [cited 2020 Jun 1]. Available from: https://hype.my/2020/185003/pornhubmalaysia-tops-asian-countries-with-most-visits-during-movementcontrol-order/. 